\title{
Process monitoring by impedance spectroscopy in the field of used-sand regeneration
}

\author{
Luca Bifano $^{1}$, Marco Weider ${ }^{2}$, Alice Fischerauer ${ }^{1}$, Gerhard Fischerauer ${ }^{1}$ \\ ${ }^{1}$ Chair of Measurement and Control Systems, Universität Bayreuth, 95440 Bayreuth, Germany, \\ mrt@uni-bayreuth.de \\ ${ }^{2}$ Foundry Institute of the TU Freiberg, TU Bergakademie Freiberg, 09599 Freiberg, Germany
}

\begin{abstract}
Summary:
It would be very advantageous if the condition of molding materials (sand-binder systems) in regenerator units used in foundries could be monitored in real-time. This work presents the results of investigations in this direction. In [1] it is shown that the condition monitoring can possibly be based on impedance spectroscopy because the resulting curves are characteristic of the material used. This has now been confirmed by measurements on a regenerator typical of the actual application.
\end{abstract}

Keywords: Foundry, regeneration process, condition monitoring, impedance spectroscopy

\section{Background}

The raw material sand is mined more than the natural regeneration of the sand deposits can compensate [2, 3]. One reason for this is that the foundry industry needs the sand to produce socalled lost forms and cores with binders like bentonite. As a consequence, used sand is now routinely recycled to save on raw material and to avoid the expensive disposal of used sand in landfills.

As the type and quality of sand play an important role in foundry applications, the qualification of the raw and regenerated materials is defined by industry regulations. In Germany, e. g., the guidelines are drafted by the Bundesverband der Deutschen Gießerei-Industrie (Federal Association of the German Foundry Industry, BDG). As yet, laboratory tests are the standard method [4].

To achieve optimum results at the lowest possible cost, the sand condition needs to be monitored during the recycling process. Our goal is to base such a condition monitoring on impedance spectroscopy. Known results from the literature indicate that the characteristics of different raw materials such as grain size distribution, crystal structure, and moisture may be distinguishable with this method. For example, [5] shows how the permittivity of bentonite depends on its water content. Ref. [6] describes the complex permittivity of sand-bentonite-water mixtures by a plausible model. We have now extended this approach and have investigated whether the process state in a state-of-the-art regenerator is observable by impedance measurements.

\section{Measurement Setup}

For our field measurements, the measuring cell presented in [1] was replaced by a cell in the form of a circular cylindrical capacitor (radial electrode distance: $1 \mathrm{~cm}$, electrode height: $10 \mathrm{~cm}$, electrode material: aluminum). In this way, the impedance measurement could be performed with a significantly smaller sample volume of the material under test (MUT). The electrodes were contacted via two coaxial cables. The electrode arrangement was fixed by a polymer sheath. The impedance of the MUT-filled cell was measured by an LCR meter E4890A from Agilent in the frequency range from $500 \mathrm{~Hz}$ to $1 \mathrm{MHz}$.

The sequence in a typical regeneration run is shown in Table 1. The speed of the regeneration progress can be adjusted by the rotational speed of the whetstone that is responsible for the regeneration effect. For this test series, the speed was respectively set to $1,830 \mathrm{rpm}$ (batch 1 , MUT 1) and 3,190 rpm (batch 2, MUT 2).

Tab. 1: Sequence of a typical regeneration run for used sand.

\begin{tabular}{|c|c|c|c|}
\hline \multirow{2}{*}{ Step } & \multirow{2}{*}{ Regeneration progress } & \multicolumn{2}{|c|}{ MUT } \\
\cline { 3 - 4 } & & 1 & 2 \\
\hline 1 & Used sand & $\mathrm{a}$ & $\mathrm{a}$ \\
\hline 2 & 5 minutes of pre-dedusting & $\mathrm{b}$ & $\mathrm{b}$ \\
\hline 3 & 10 minutes of regeneration & $\mathrm{c}$ & $\mathrm{c}$ \\
\hline 4 & 20 minutes of regeneration & $\mathrm{d}$ & $\mathrm{d}$ \\
\hline 5 & 30 minutes of regeneration & $\mathrm{e}$ & $\mathrm{e}$ \\
\hline 6 & 10 minutes of post-dedusting & $\mathrm{f}$ & $\mathrm{f}$ \\
\hline
\end{tabular}

For the impedance measurements the cell was filled with the MUTs, a frequency sweep was run 5 times, and the cell was emptied again. This was repeated 5 times for each MUT.

\section{Results}

Figure 1 shows the respective mean value curve of the different regeneration states of MUT 2 as 
Nyquist plots. The maximum uncertainties for the real and imaginary parts were $13.64 \%$ (at $f=$ $14 \mathrm{kHz}$ ) and $16.17 \%$ (at $f=48 \mathrm{kHz}$ ) for MUT 2b. At other frequencies and for other MUTs, the uncertainties were well below these values. For example, for the MUTs $2 \mathrm{c}$ and $2 \mathrm{~d}$, the maximum uncertainties of the real and imaginary parts did not exceed $4 \%$. The measurements are obviously quite reproducible, although refilling the measuring cell does not lead to the exact same conditions. This reproducibility justifies our working with mean-value impedance curves.

The impedances shift to higher values as the regeneration progresses (Fig. 1). The initially observed semicircular arc at high frequencies (MUT 2a-c) disappears and the Nyquist curves become steeper. This indicates that the regeneration process reduces the electrical conductivity of the material composition (higher impedances) and that it removes components from the sand (disappearing semicircular arc). This very removal of components is the aim of the process and, as shown, it can be monitored by impedance spectroscopy.

The same observations have been made for MUT 1. Due to the slower movement of the whetstone, the regeneration progress is slower, and this is revealed by the impedance data. This will be shown in more detail in the full contribution.

\section{Conclusion}

The current field tests corroborate our conclusions from laboratory measurements on sand/binder mixtures, viz., that impedance spectroscopy is suitable for monitoring sand regener- ation processes. Of course, the method will unfold its full potential when an industrial-grade LCR meter rather than laboratory equipment is used.

\section{Acknowledgement}

This work was supported by the German Federal Ministry for Economic Affairs and Energy, grant number ZF4152305DB8.

\section{References}

[1] L. Bifano et al., "Investigation of complex permittivity spectra of foundry sands," Tech Mess, Vol. 87, pp. 372-380, May 2020.

[2] J. Götze, M. Göbbels, Einführung in die Angewandte Mineralogie (Introduction to Applied Mineralogy; in German). Berlin: Springer, 2017.

[3] N. N., Sand and sustainability. UN Environmental Programme, Geneva, Switzerland, 2019.

[4] W. Tilch, H. Polzin, and M. Franke, Praxishandbuch bentonitgebundener Formstoff (Practical manual for bentonite-bound molding material; in German). Berlin: Schiele \& Schön, 2019.

[5] H. Kaden et al., "Low-frequency dielectric properties of three bentonites at different absorbed water states," J. Colloid Interface Sci., Vol. 411, pp. 16-26, Dec. 2013.

[6] T. A. Belyaeva et al., "The effect of very low water content on the complex dielectric permittivity of clays, sand-clay and sand rocks," Meas. Sci. Technol., Vol. 28, No. 1, (8pp), Jan. 2017.
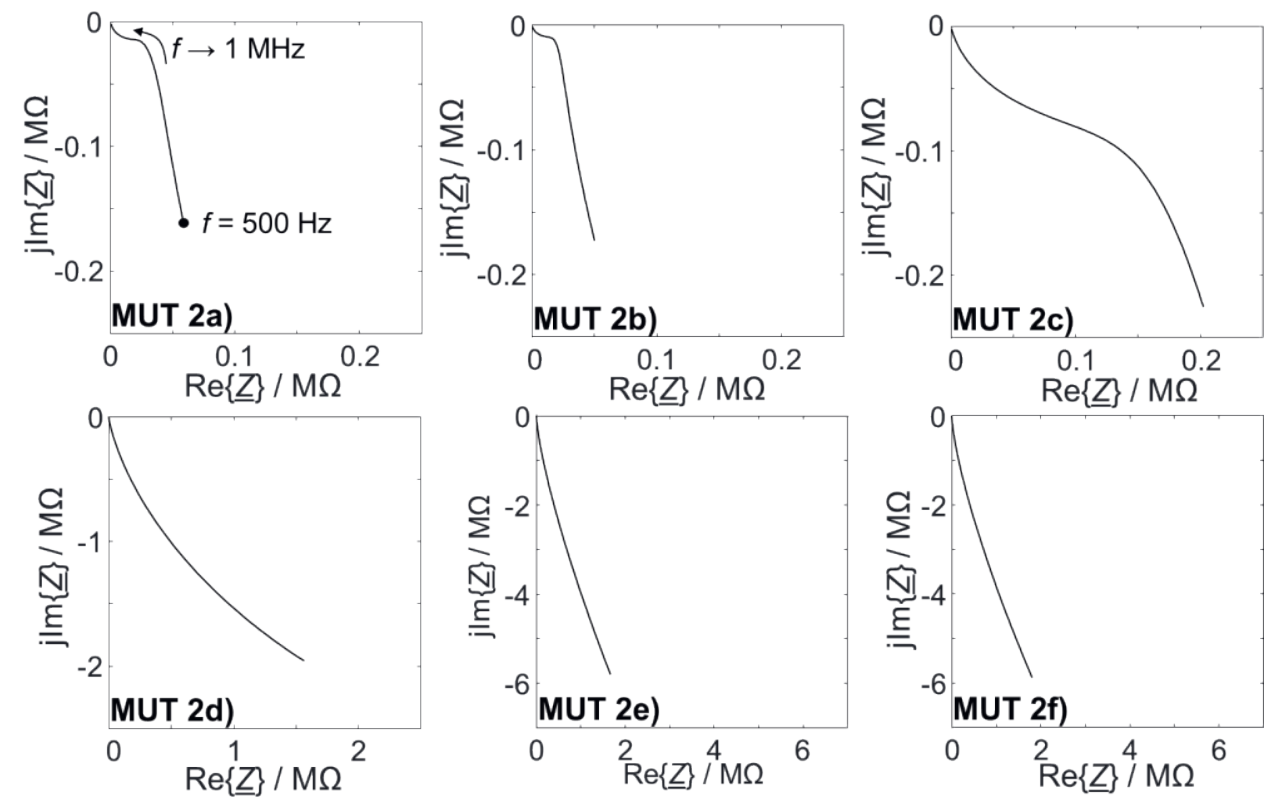

Fig. 1 Measured test-cell impedance with MUT 2a through $2 f$ during the regeneration process. 